\title{
Agricultural Big Data Analytics and the Ethics of Power
}

\author{
Mark Ryan ${ }^{1}$ \\ Accepted: 11 November 2019 / Published online: 18 November 2019 \\ (c) The Author(s) 2019
}

\begin{abstract}
Agricultural Big Data analytics (ABDA) is being proposed to ensure better farming practices, decision-making, and a sustainable future for humankind. However, the use and adoption of these technologies may bring about potentially undesirable consequences, such as exercises of power. This paper will analyse Brey's five distinctions of power relationships (manipulative, seductive, leadership, coercive, and forceful power) and apply them to the use agricultural Big Data. It will be shown that ABDA can be used as a form of manipulative power to initiate cheap land grabs and acquisitions. Seductive power can be exercised by pressuring farmers into situations they would not have otherwise chosen (such as installing monitors around their farm and limited access to their farm and machinery). It will be shown that agricultural technology providers (ATPs) demonstrate leadership power by getting farmers to agree to use ABDA without informed consent. Coercive power is exercised when ATPs threaten farmers with the loss of ABDA if they do not abide by the policies and requirements of the ATP or are coerced to remain with the ATP because of fear of legal and economic reprisal. ATPs may use ABDA to determine willingness-topay rates from farmers, using this information to force farmers into precarious and vulnerable positions. Altogether, this paper will apply these five types of power to the use and implementation of ABDA to demonstrate that it is being used to exercise power in the agricultural industry.
\end{abstract}

Keywords Agricultural big data $\cdot$ Data analytics agriculture $\cdot$ Agricultural technology provider $\cdot$ Ethics $\cdot$ Power $\cdot$ Artificial intelligence

\section{Introduction}

The world's population is increasing, and it is estimated that we will need to produce $70 \%$ more food by 2050 to sustain this growing population, while our ecological footprint is double the level that it should be (Food and Agricultural Organisation,

Mark Ryan

mryan@kth.se

1 KTH Royal Institute of Technology, Stockholm, Sweden 
The UN 2009). This growth can come from an additional $10 \%$ of new farmland, while the other $90 \%$ growth needs to come from existing land (Popa 2011). Farmers need to improve their yields, make better management decisions, and minimise waste in order to ensure an equitable and sustainable future. One possible solution to our agricultural needs is the use of technology to improve farming efficiency.

One method being proposed is the use of agricultural Big Data, artificial intelligence and machine-learning technologies to determine better farming practices and decision-making, which I will loosely categorise as agricultural Big Data analytics (ABDA). However, the use and adoption of these technologies may bring about potentially undesirable consequences, such as the five cases of abuse of power highlighted by Brey (2007): manipulative, seductive, leadership, coercive, and forceful power. This paper will focus on these five types of power and demonstrate how they may be exemplified in the use and implementation of ABDA.

"The Agricultural Industry" section of this paper will provide a background account of the agricultural industry and how it has developed in recent decades, particularly focusing on the number and range of takeovers, acquisitions, mergers and developments. It will help illustrate how there is a funnelling of agribusinesses and a widespread vying for companies to propel the ABDA market.

"Agricultural Technology" section will concentrate on agricultural technology developments, before focusing on the emergence of agricultural technology providers (ATPs) and their relationship to the farmer. It will show the uses of ABDA and how it benefits the farmer and the industry.

"Theories of Power" section will highlight Mark Haugaard's political theory of 'power over' and 'power to'; how power has traditionally been applied to political entities but can now also be exemplified by corporations; and how Brey's theory of power illustrates five types.

"Ethical Considerations in Power Relationships" section will give a brief overview of how power has implicit and explicit ethical underpinnings in how it is achieved and exercised. It will provide explanations of how each of the five types of power have their own fundamental ethical concerns.

"The Power of ATPs in Agriculture" section will apply these five types of power to the use and implementation of ABDA to demonstrate that it is being used to exercise power in the agricultural industry. I will demonstrate that ATPs can use ABDA as a form of manipulative power potentially using it for cheap land grabs.

I will show how ATPs use ABDA as a form of seductive power, forcing farmers into situations that they would not have chosen otherwise (installing monitors around their farm; prohibiting access to their machinery; and control of their farm, generally). ATPs also demonstrate leadership power because of their authority in the agricultural sector, which often blurs the lines between informed consent and blind acceptance of policy surrounding ABDA, such as data ownership. Coercive power is also exercised by ATPs in the manner that farmers are threatened with the loss of ABDA if they do not abide by the policies and requirements of the ATP or are coerced to remain with the ATP because of fear of legal and economic reprisal. Finally, ATPs may use ABDA to determine farmers' willingness-to-pay, using this information to force farmers into precarious and vulnerable positions. The evaluation of these five power types in the use and implementation of ABDA will provide 
a theoretical account of power distributions. It lays the groundwork for further research on agricultural power dynamics, providing the basis for the articulation of normative, prescriptive work.

\section{The Agricultural Industry}

Before analysing the development of agricultural Big Data analytics (ABDA), it is important to understand developments in the agricultural industry in recent years to identify the role that ABDA will play. There have been many changes in the industry in recent years that illustrate the direction that it is going, and why ABDA will play such a pivotal role in this growth. The agricultural industry would have typically comprised of four distinctive agricultural markets: farm equipment, fertilizers, chemicals, and seeds. From the 1990s to the mid-2000s there was a large shift in the agricultural sector, where these four categories were reduced to three. As a result of aggressive mergers and acquisitions, seeds and chemicals are now a single category (Pham and Stack 2018).

Previously, chemical companies and seed companies were separate, but this has completely changed with chemical companies acquiring seed companies: Bayer (their own development and the purchase of Monsanto); BASF (their own seed business and their recent acquisition of nearly $\$ 6$ billion of Bayer's business); the merger between Potash Corp and Agrium; ChemChina (purchase of Syngenta for US\$46 billion); and Dow and DuPont merger for US\$77 billion (developing the DuPont Pioneer seed business). These are just a few of the most high-profile cases and does not factor in the plenitude of mergers and acquisitions of smaller companies in the seed industry and in other areas, such as AI start-ups, weather data organisations, and drone manufacturers (Janzen and Ristino 2018; Kshetri 2014; PrecisionHawk 2018).

One area of business that has rapidly developed in recent years is data retrieval, processing, analytics and prescriptive advisory services. Data has become a valuable commodity in the agricultural industry, evidenced by the sheer volume of agribusinesses purchasing technology start-ups, investments into their own data systems, as well as their push towards digitising the farm. Data science is becoming big business with an abundance of acquisitions, mergers and developments in the agricultural sector. For example, Monsanto bought the agricultural software and hardware company Precision Planting Inc. in 2012 for \$210 million and the climate monitoring company The Climate Corporation in 2013 for $\$ 930$ million; Du Pont Pioneer has created agreements with John Deere; the farm supplier Land O'Lakes purchased the satellite-imagery company Geosys; BASF bought the tech company ZedX Inc. in 2017; and DowDupont purchased the ag data start-up Granular for $\$ 300$ million and entered a venture with weather analyst DTN/The Progressive Farmer (Janzen and Ristino 2018; Kshetri 2014). John Deere paid \$305 million to purchase the company Blue River Technology, who has developed robots that attach to tractors that can 'analyze crops and apply fertilizer and pesticides plant-by-plant' (Bunge 2017). The most recent and important acquisition of recent times is Bayer's acquisition of Monsanto for $\$ 66$ billion. Their data and knowledge portfolio played a strong role in the 
lengthy negotiations between the companies and required an agreement by Bayer to sell sections of its business to BASF by antitrust regulators. A part of those negotiations involved the transferral of their digital farming business Xarvio to BASF.

With all this investment in data acquisition and analytics, why is this area attracting so much attention from agricultural conglomerates? What is diverting their interest from their traditional business as chemical and seeds providers? The agricultural industry accounts for $10 \%$ of the world's domestic product, generating nearly $\$ 5$ trillion annually (Murray 2007). The giants that dominate this market are becoming increasingly interested in the use and implementation of data analytics in the agricultural world. The agricultural data market is big business and is set to grow rapidly in the coming years. For example, Monsanto has estimated that data analytics will increase global crop production levels by $\$ 20$ billion a year in the future (Bunge 2017). Multinational agribusinesses would have traditionally sold physical products and resources to farmers but have now branched out into the data analytics world because of profitability and increased agricultural marketplace dominance. ${ }^{1}$ The agricultural data market is set to become a huge income-generator for agribusinesses and most are competitively vying for this lucrative market. There is the realisation that the future of agriculture lies in technological development.

\section{Agricultural Technology}

Advanced technological innovations are not necessarily a new thing in the agricultural sector, with precision agriculture, GM crops, and the adoption of robotic technologies in livestock management going back over two decades (GMO Answers 2014; Hoard's Dairyman Staff 2012; The National Museum of American History 2018). A lot of the physically difficult, labour-intensive work is set to be done by or assisted by, emerging technologies. For example, robots are already heavily integrated into the livestock sector, taking on the jobs of animal identification and feeding, milking, shearing, weighing and even slaughtering livestock (Popa 2011, p. 289). UAVs are being used to collect data about the farmland and its surrounding area for crop management, and John Deere and NASA are developing self-driving tractors (NASA 2018).

Technologies will increase productivity and decrease economic, physical and emotional burdens associated with such activities. They are being implemented to remove the difficult, cumbersome, tedious and unwanted work, leaving the farmer more time to intensify, develop, expand or otherwise improve their farm. For example, artificial intelligence is allowing the improvement of resource productivity; develop unmanned agricultural machinery; implementing computer vision techniques to model pattern recognition; cattle breeding and milking; effective algorithmic planning and improved knowledge for better decision-making (Dengel 2013;

\footnotetext{
1 There are, of course, non-profit, open source providers that are attempting to provide an alternative to farmers. However, they are minimal and the level of technology is nowhere near those of the agribusinesses.
} 
Griepentrog et al. 2013; Bernardi 2013; Fleischmann et al. 2013; Scheuren et al. 2013). A recent agricultural technological development is data retrieval and analytics to assess specific patterns and prescribe alternatives with regards to planting, watering, weeding, harvesting, and general care of their farm. Over the past decade, we have witnessed a massive shift towards more expertly assessed data-focused prescriptions for farmers.

Having access and analytic capabilities to widely spanned farming data allows for a much more effective approach to predictive and prescriptive analysis. The past decade has seen the emergence of the agricultural technology provider (ATP), which is a business component of highly successful corporations, such as Monsanto, Bayer, John Deere, Pioneer, and BASF. The only thing that is being sold is knowledge, which is different from the traditional business of fertilizers, seeds, farming machinery or chemicals. There is a shift from physical products to knowledge-based services. This is not to say that agribusinesses are ignoring their traditional business, but that they are intertwining and embedding them within this service.

The process involves the farmer entering into an agreement with an ATP to provide their farm data or agree that the ATP can collect it from their farm. Some of these types of data collected include animal activities, soil moisture, land irrigation, rainfall levels, temperature, crop growth patterns, and soil nutrient levels (Bennett 2015; Kamilaris et al. 2017). The ATP typically installs a range of data retrieving devices on the farm, the farmer's machinery, and the surrounding area, in order to obtain persistent, far-reaching, quantitative data. The ATP analyses the data from the farm and assesses it with datasets acquired from other farms; along with regional analysis, satellite imagery, and additional agricultural data acquired by the ATP. The ATP plots and calculates the most efficient way to use to ensure maximum sustainable yields for the farmer. The farmer can purchase that data from the ATP on a per acre pricing schema. They provide farmers with prescriptive farming recommendations derived from their data, something that would not have been possible in the past (Bennett 2015).

They do this by installing monitors and sensors on farm machinery, drones, and around the farmland itself. The farmer's data is collected and analysed against the ATPs' datasets, which comprise of agronomic data, datasets from other farmlands, weather datasets, and the knowledge of the company. They analyse the farmer's data with data retrieved from other farms and prescribe predictive evaluations for the highest possible yield while improving productivity and increasing profit. Advice is provided on topics such as correct seeding, planting, weeding and harvesting times, as well as providing feedback about market valuations and sale prices. ATPs are providing analytical services to the farmer about his farm to an extent that was not previously possible. However, prescriptive data analytics is not a new thing and is already quite common in many areas of business, healthcare and society, and ABDA is set to become a very important component within agriculture as farmers are pushed to deliver higher yields with fewer resources. Data analytics appears to be one of the answers to many of the challenges that the agricultural industry faces. However, it is important to analyse if the use of ABDA is causing a power shift between the farmer and the ATP and how this power shift may be problematic. 


\section{Theories of Power}

The concept of power has been a topic of debate since the 1970s and 1980s, with many social theorists proposing different definitions of power. What appears to be raised repeatedly is that there are different formulations of power, categorised as 'power to' and 'power over' (Göhler 2009, p. 28). 'Power over' refers to a provocation, action, or behaviour that would induce a 'power over' another; it is fundamentally relational to another, whether it is an individual or group of individuals. Whereas, 'power to' refers to the power to do something, which may or may not includes the involvement of others. It is not necessarily relational, as one can realise empowerment without the involvement of others. 'Power over' requires the relational involvement of another, whereas 'power to' does not. 'Power over' refers to the diminishment of another's autonomy that the power is being actioned over. Whereas, 'power to' is the ability to accomplish an activity, without necessarily subjugating another's autonomy.

The relationship between the two types of power can be understood in the manner that 'power to' is a precondition for 'power over' to be exercised, or else 'power to' can be understood as a type of power in itself, completely unrelated to 'power over' (Göhler 2009, p. 31). In the former instance, 'power to' would act as a precondition, a type of ability to exercise 'power over', before demonstrations of 'power over' come into effect (if they even do so). 'Power to' is the potential ability to exercise a 'power over' individuals or groups of individuals. In the second understanding of 'power to', it can be defined as a separate ability to do something, while not necessarily exerting any kind of 'power over' other agents.

Fundamentally, both definitions of 'power to' are more akin to the capacity to do something and are largely confined to a potential, latent disposition (Göhler 2009 , p. 31). Therefore, 'power to' and 'power over' are quite different, particularly in the effects that both forms can have on others. 'Power over' is a play between actors attempting to receive the best possible outcome for themselves and reduces or increases the autonomy of the individual(s) that it is being exercised, or not exercised, over. Whereas, 'power to' can be exercised without affecting anyone's autonomy. However, this is not to say that 'power over' is negative because there are instances where it is legitimised, as in the case of authority (Clegg and Haugaard 2009, p. 403). Political parties elected in a democratic way to exercise 'power over' non-coercively (Haugaard 2012a, p. 78). Haugaard and most social scientists are talking about political power and how it is implemented by governmental bodies on its citizens, whereas, for the purpose of this paper, we want to identify power relationships involving corporations, such as ATPs.

Ulrich Beck (2005) states that the old process of power dynamics was confined to nation-states, where there were limitations on geographical, physical territory. With the dawn of neoliberalism and the increasing power of companies, it brought about a shift in power to transnational, mobilised, and divergent power structures. Companies and businesses are not confined to the standard international order of previous power dynamics. 'In its place, a new deterritorialized game of power politics has taken shape where the enhanced mobility 
of business and capital is said to give it an edge over territorially bound states' (Allen 2009, p. 159). Large multinationals are breaking out of the traditional power boundaries set in place by nation states. There is a meta-power taking place, whereby globalisation allows corporations to fight for power and rewrite the territorial power parameters previously in place. Corporations are becoming transnational, blurring the control and boundaries of national and international policy, law and power. Large agribusinesses demonstrate one such example of this power. However, before demonstrating ATP exertion of power, it is important to classify different kinds of power that may be exerted in these kinds of relationships.

Philip Brey defines five types of 'power over' and applies these types of power to how specific technologies enable and ensure certain power structures. Brey (2007) classifies different exercises of power into the following categories: manipulation, seduction, leadership, coercion, and force.

Manipulation is the exertion of power to get people to behave in a certain manner while restricting pieces of information or deceiving them in some manner (Brey 2007). ' $A$ manipulates $B$ when, by doing $x$, $A$ causes $B$ to do $y$ which $B$ would otherwise not have done, without $B$ 's knowing that (1) $A$ is doing $x$, or (2) that $A$ is doing $x$ to cause $B$ to do $y$, or (3) that $A$ has reason $r$ for wanting $B$ to do y' (Brey 2007).

Secondly, seduction is a type of 'reward power' towards individuals that gives them the incentive to do a certain action: If A promises B of a reward if they do $\mathrm{x}$, which B would not have done otherwise (Brey 2007). While coercion incurs a negative reason for action, seduction entices through a positive incentive (Brey 2007). There is generally a greater control over one's decisions in seduction than coercion.

The exercise of power in a leadership context does not necessarily depend on any of the other four types of powers, but there may be an overlap between them. ' $A$ leads $B$ when, by doing $x, A$ causes $B$ to do $y$ which $B$ would otherwise not have done because $B$ accepts the right of $A$ to require y (i.e. because of $A$ 's authority) or because $y$ is accepted as reasonable in the circumstances of $B$ (i.e. $A$ persuades $B)^{\prime}$ ' (Brey 2007).

Coercion is defined as a situation where 'an agent $B$ performs actions because the controlling agent $A$ has made $B$ believe that if he does not perform these actions, he will be penalized by $A^{\prime}$ (Brey 2007, get page reference, p. 7). It requires 'negative incentives for action' (Brey 2007, p. 7). Social theorists have commonly understood power in a coercive manner, whereby one individual or group of individuals get others to do things they would not otherwise do without threat, sanctions, or punishment (Haugaard 2003, p. 87).

The example of power by force can be understood as follows: ' $A$ forces $B$ when, by removing from $B$ the effective choice to act otherwise, $A$ causes $B$ to do $y$ which $B$ would otherwise not have done' (Brey 2007). This essentially prohibits B from any other actions except the one forced upon them by A. All five types of power will be evaluated through several different examples of ABDA use and implementation to evaluate potential ATP power dynamics. 


\section{Ethical Considerations in Power Relationships}

Historically, there was a shift from physically forced dominating power to a more nuanced and indirect display of power, 'a move from obedience based upon coercion, to compliance based upon internalized self-restraint, which is theorized as the "civilizing process", (Haugaard 2012b, p. 36). Essentially, power over has a dualistic nature, it can form a type of domination over individuals but it also 'constitutes the conditions of possibility for democracy, and thus is normatively desirable' (Haugaard 2015, p. 147). While power is required for democratic systems to function, it can also be abused, leading to curtailments and infringements upon individuals' liberties, autonomy, dignity and fundamental human rights.

There has been a great deal of debate about whether or not power over is an act of agency by an individual or group of individuals, or a societal construction set in place to ensure power structures occur (Göhler 2009, p. 30). However, even if it forms as a result of social structures, the exercise, enforcement and abidance of power are acts of agency (Haugaard 2012a). Essentially, 'different groups, decision makers and organizations caught up in spatial and temporal arrangements that often combine anything from the erosion of choice, the manipulation of outcomes and the threat of coercion with the closure of possibilities, the assent of authority and the open-ended qualities of seduction and persuasion' (Allen 2009, p. 158).

Issues of power dynamics have been implicit within philosophical deliberations since the time of the ancient Greeks, with Plato's Republic describing a wide array of power structures within his work. ${ }^{2}$ The issue of political power and control has been a fascination amongst political philosophers, with Hobbes declaring that power resulted from a social contact between people and the state as a means of protection from their fellow citizens (Hobbes 1968). ${ }^{3}$ Whereas John Locke proposed that we entered into the social contract and gave power to governing kings in order to prosper. ${ }^{4}$ What has underpinned definitions of power is the fact that one agent, or group of agents, may affect others' decisions, actions, and behaviours, whether this is taken or given, and for their benefit or disadvantage. Therefore, how power is achieved and exercised may have strong ethical implications.

Lukes (1974) and Connolly (1974) both propose that there is a responsibility on those with power to change things for the better. However, often the agent in power may not necessarily have the capacity to change certain situations or may they necessarily be responsible for doing so (Greene 2019). The ascription of power does not necessarily imply what they should do in a situation, even if it

\footnotetext{
2 These examples can be illustrated through the allegory of the cave (leadership power); the philosopherkings use of the noble lie (manipulative power); the analogy of the mighty beast being tamed through seduction and persuasion, which represents the Athenian people (seductive power); the state taking children away from their biological parents to be communally brought up (coercive power); and tyrannical governments controlled through fear (forceful power).

${ }^{3}$ Power was created out of necessity for self-preservation, where individuals ceded some of their rights for protection.

${ }^{4}$ People came together willingly, rather than out of fear, and allowed a sovereign ruler power to lead the nation.
} 
is noted that they are responsible. For example, what levels of free competition should be permitted and when should governments interfere: "what is the ethical basis for using government intervention to reduce "free competition" in order to promote some special group's self-interested sense of "fair competition"?' (Sykuta 2012, p. 21).

Therefore, power has the potential to be a clear ethical concern in a wide range of situations, most notably, the five types of power already outlined. For example, manipulative power can result from lying, ensuring opacity, or deception, which all have a long history of ethical analysis in the philosophical tradition (Aquinas 1972; Augustine 1952; Kant 1996; MacIntyre 1995; Siegler 1966). Truth-telling, honest, and transparency are commendable characteristics to have in the consequentialist tradition because of the unknown harms caused by it and it undermines societal value in truth-telling; whereas, in deontology, truth-telling is typically characterised as a moral rule to abide by; while in virtue ethics, honesty is a virtue that we must aspire to.

Reward power refers to situations where the individual is awarded for doing an action that they would not have otherwise done. During fair transactions of goods and services, this is not concerning, but where the awarder puts the health, safety, and wellbeing of the awardee in jeopardy, then it becomes ethically problematic. This may come in the form of employment where one's life is constantly at risk, paying poor communities to accept pollution in their area, or offering economic incentives to families to give their children up for adoption. The abuse of reward power can most emphatically be addressed by Kant's moral imperative to not treat our fellow human beings as ends in themselves (Kant 1996).

Leadership power involves the control over others' actions by means of authority or being viewed as an expert or leader in the area. It alludes to a sense of knowledge and authority on a matter, and thus, having power to guide others' views and behaviours. Those in roles of leadership have a responsibility towards those whom they are leading, so as to not cause them undue harm. In many situations, those who assume or placed in leadership roles should be held accountable during incidences resulting from their negligent actions.

Coercive power involves structural constructs that 'constitute the rules of the game or dispositional power, which preclude certain actions' and 'are modes of limiting interaction, which create conditions of possibility' (Haugaard 2012b, p. 38). Freedom is an essential component in individual's lives, the freedom to make decisions about your life and the freedom from intervention of these decisions (Brey 2007). The exercise of coercive power restricts individuals' abilities to make autonomous decisions about their lives. It restricts one's positive liberties to make one's own choices (Berlin 1958).

There was a shift from direct power over as domination in the form of violent punishment, towards disciplinary power. Forceful power is essentially the forceful removal of one's liberties, most particularly, one's liberty of physical self-control (Berlin 1958). Forceful power would restrict individuals' freedoms, by restricting freedom of movement, communication and association (Berlin 1958). It would remove individuals' rights to go about their business free from interference. 


\section{The Power of ATPs in Agriculture}

I will demonstrate that the use of ABDA has the potential to be used as a form of power in the agricultural industry. I will evaluate the types of power effects that ABDA can have in society, both at a farmer level, and the wider industry level. It will be a theoretical account of the distribution of power, rather than a normative or prescriptive account. This is the first step towards categorising and defining the power dynamics resulting from ABDA. I will evaluate several examples showing how ABDA is exercised through the five power types: manipulative, seductive, leadership, coercive and forceful power.

\section{Manipulative Power}

Agribusinesses are set to benefit from the collective pool of data received from farmers. Not only will they cater to the needs of individual farmers, but they will also use this data collectively as a resource for predicting generalities, anomalies, and agricultural productive capacities. They would be able to have clear general estimations of different crop yields, yields by location, size and division of land. There is the possibility to aggregate, forecast and, in turn, set targets for farmers, based upon this data. Sykuta (2016) rightly points out that the data retrieved from one farmer is generally more important and weightier than an individual user's data on Amazon, Google or Facebook. While these companies aggregate data from millions of users, an individual's data is of quite minimal worth, it is only when it is aggregated that it is useful.

The data retrieved about a farmer's business consists of a much larger shareholding in the overall data processed and aggregated by the agribusiness. ATPs are trying to attract as many farmers as possible to join their network to provide more effective prescriptions. The very basis of providing effective recommendations lies on the fact that large data repositories are required. The greater the quantity, type, an array of farm datasets available, the more detailed, accurate, and far-reaching these prescriptions will be. Therefore, receiving individual farm data is both beneficial for the ATP and the farmer. It is beneficial for the ATP because they can add these datasets to their data repositories in order to improve their algorithms, and it is beneficial to the farmer because they will receive better recommendations about their farm. However, this kind of data exchange may lead to manipulative power dynamics, if ATPs use this data for nefarious means that the farmer is unaware of, such as farm acquisition and land grabs.

As a result of having the farmer's data, there is the possibility that agribusinesses will be able to determine profitable from unprofitable land, granting them the opportunity to make acquisitions of farmland that will yield the highest premium (Sykuta 2016). The ATP may manipulate the farmer when, by using and integrating ABDA, the ATP causes the farmer to potentially compromise their farmland which they would otherwise not have done, without the farmer's knowing that the ATP is doing this [adopted from Brey 2007]. Their farmland may be compromised as a result of 
using ABDA in several ways: (1) The ATP may purchase land that they know to be of high quality, for very little; (2) Implement restrictive and economically aggressive policies on some of their customers until they are forced to sell their land at a heavily reduced price to the agribusiness or a partner company; (3) There is the possibility that they will identify problematic farmland and use this information to undercut the farmer's asking price, either directly or through one of their partners/affiliates.

All three of these examples would potentially drive land out of the hands of the farmer as a result of the ABDA information retrieved about the farm. While the purchase of farms is not a primary business of agribusinesses, it still occurs and may increase with the prospect of profitability and power in the industry (Heubuch 2016; New Eastern Outlook 2015). In all three situations, the farmer is seriously disadvantaged by the situation, which they would not otherwise have chosen if they did not have to. While we can envision situations where a farmer just desperately wants to sell their land, doing so at an extremely unfavourable deal is against their interests, if a better deal was available if they had not provided ATPs with their farm data. This is a clear example of manipulative power: farmer provides the ATP with information that would either seriously harm their ability to sell their land or manipulate them into selling it at a far lower cost than they had anticipated, without knowing that was a possible use of their data, and which they would not have doing knowing that this would be the outcome.

\section{Seductive Power}

The use of seductive power can also be exemplified in monopoly employment and services, where the exercise of power is the promise of work or a service that is 'scarce and important to the subject of power, and there are few alternative ways to get these benefits' (Brey 2007). A seduces B with the offer of a good or service, such as ABDA, and this resource is scarce because very few agents can provide this service to A. Seduction entices an agent into doing an action for the use of a monopoly good or service. ATP seduces the farmer with the offer of ABDA if the farmer does $\mathrm{x}$, which they would not have done otherwise, for the benefit of the monopoly good or service. An ATP may seduce a farmer with the promise of using their scarce service (ABDA) to improve their yields, productivity and profit levels; which they cannot otherwise do with their current levels of knowledge and abilities.

Farmers provide ATPs with data, which they analyse in order to provide the farmer with recommendations. In this relationship, one of the most fundamental prerequisites is that the farmer is open to sharing his data with the ATP. Without data-sharing, the ATP cannot offer tailored, specific advice to the farmer. Therefore, the provision of data is an essential component in this interaction. This provision of service is not some kind of altruistic activity, because the ATP benefits from the farmer's data. ATPs aim to have an expansive repository of farm marketplace data in order to gain a competitive edge in the data-provider marketplace (Coble et al. 2018, p. 84). Many ATPs are offering free or low-cost analysis to farmers in order to amalgamate large data resource-pools, which will create richer and more dynamic databases. 
ATPs provide a service to the farmer, one that combines information retrieved from the farmer's land with aggregated and contrasted datasets of similar farms, soil types or climatic locations. Asides from empirical data retrieved from farmlands, there is the integration of scientific analysis, research and knowledge before the results are disseminated to the farmer. If this service is not offered, then the promise of agricultural Big Data as a powerful resource for profit-generation and efficiencymaximisation will not be realised. Otherwise, farmers are in the same position as previously-making decisions based on best-guess approximations, while still faced with the monumental pressure to produce $70 \%$ more grain with the same land. ${ }^{5}$

Therefore, if farmers do not have access to ABDA, they may not be able to keep up with the pressures to grow their output and may become vulnerable to marketplace demands. Those using it will be able to produce greater yields, at lower costs, and undercut their competitors using ABDA. The relationship between the ATP and the farmer is fundamentally underpinned by data sharing. The farmer must share their data to benefit from the ATPs' data analytics platforms, and this analytics can only be given after the provision of the farmer's data. In itself, not entirely problematic, but it is important to examine the parameters of data sharing and distribution in order to identify potential issues in the relationship between ATPs and farmers.

Data is a valuable commodity, and ATPs are aware of this. They are putting stringent controls and restrictions to secure their data, protect their $R \& D$, and ensure control of the market. For example, the ATP instils prerequisites prior to their arrangement to retrieve and analyse data from the farmer's land. There is a power seduction to improve, increase and grow one's farm, but farmers need to abide by the restrictions that the ATP lays out, which the farmer would not have done otherwise. The farmer has to install monitoring devices and sensors around their farm, on their farm machinery, and allow drones to gather data from above their farm. For example, Monsanto prohibits farmers from accessing their data that is retrieved; John Deere prohibits farmers from tampering with their machinery as it is seen as an intellectual property infringement; Pioneer and Monsanto require farmers to be their seed customers prior to using their ABDA (Sykuta 2016).

ATPs prohibit farmers from accessing data that they are producing, or in any way altering the data compiled from the organisation (Sykuta 2016). The farmer is left open to investigation, analysis, and questioning from the company, to ensure that they are abiding by these policies. The farmer's crops, yields, mobility and soil fertility are now tracked-and-traced in a manner never before seen. The farmer is seduced by the potential benefits received from ABDA and agrees to terms and conditions that they would not have done otherwise. They abide by the prohibitions from accessing their machinery, allow themselves to be analysed and scrutinised by

\footnotetext{
${ }^{5}$ Carolan (2017) conducted empirical research into the use of Big Data and analytics methods within food systems and agriculture. He interviewed 18 Iowa farmers using Big Data; 14 companies working in the area of agricultural big data; and 19 interviews with food system entrepreneurs. Many of the respondents said that they were aware of population growth figures. They were also aware that the current methodologies being used were unsustainable because of the environmental effects and the deficiency in the supply-chain to respond to larger populations. Others stated that they required these data analytical tools in order to improve yields and make better decisions.
} 
the ATP, and often withdraw ownership of their data property to the ATP; all things that they would not have done so otherwise. The farmer has to endure restrictive measures on the control of their farm, a profession that farmers pride themselves on having control over their own land and business. The seductive power exhibited by the use of ABDA may potentially jeopardise the farmer's autonomy and control over their environment if these power dynamics are not addressed.

\section{Leadership Power}

When we put our ATP-farmer relationship into the leadership definition, and frame it with a clear demonstration of leadership power, it looks like this: the ATP leads the farmer when, by agreeing to their specific terms \& conditions, the ATP causes the farmer to do enter into a data-sharing agreement without informed consent and clarity about data ownership, which the farmer would otherwise not have done because the farmer accepts the right of the ATP to require the farmer to enter into this agreement (i.e. because of the ATP's authority). However, before demonstrating this example of leadership power, it is important to understand recent activities in relation to establishing data ownership in the industry. In 2014, multiple agricultural producers in the US outlined the difference between farmer's ownership of data and the data owned by the agricultural company providing the technological service. ${ }^{6}$ It was agreed that the data created on the farm belongs to the farmer, but the advisory information that is generated after analysing the farmer's data is owned by the ATP (Sykuta 2016, p. 66).

Despite this agreement, there is a concern that the dynamics created between the ATP and the farmer will cause a severance between the creator and owner of data; with the farmer having no real access to their data. Even where the farmer can access their data, they have very little opportunity to effectively unpack this information, let alone productively use these findings. These technologies require a high level of programming skills, data analytics knowledge and data management capabilities, that most farmers will not possess, thus placing a dependency on the ATP. Sykuta (2016) highlights that one of the most limiting factors in the application of ABDA is the lack of competency of the average farmer to effectively assess their data in any meaningful way. There is a reliance on larger organizations with the power, resources and ability to effectively transform the raw data acquired into an understandable and actionable context.

However, people pay companies to carry out work for them that they cannot do themselves all the time, without carrying out problematic or ethical issues. What is of concern are the issues that arise as a result of the relationship between the ATP and the farmer, in terms of what can and cannot be done with their data, the dependence created as a result of this relationship, and the restrictions placed on

\footnotetext{
${ }^{6}$ The agricultural data agreement between a range of America farm associations, companies and bureaus implemented the 'Privacy and Security Principles for Farm Data', commonly referred to as the 'Core Principles' (Janzen and Ristino 2018). This partnership included Monsanto, American Farming Bureau Federation, John Deere, and Pioneer (Sykuta 2016).
} 
farmers as a result. These are the requirements initiated by the ATP for the provision of ABDA. For example, a lot of farmers are not even aware of data ownership, the agreements that they are entering, or what can be done with their data. For example, a 2016 survey conducted by the American Farm Bureau Federation of 400 farmers, showed that a disproportionate number of farmers did not know about their data or what the terms and conditions implied in their agreement: $55 \%$ did not know if they own their data; $54 \%$ were unsure if their data could be shared with a third-party by the ATP; but surprisingly, '[s] eventy-seven percent are concerned about which entities can access their farm data and whether it could be used for regulatory purposes' (American Farm Bureau. 2016).

This empirical data helps us to understand that a majority of farmers that are entering agreements with ATPs are unaware of what they are agreeing to, who owns their data, and what it can be used for. This is not to say that they do not care, because $77 \%$ of farmers that are concerned about what is being done with their data demonstrate that the majority are not handing over their data without any care or concern about it, but rather, they are doing so because of expertise power exerted by the ATP that they would benefit from it, without fully understanding what they are agreeing to. Farmers are being advised by ATPs; they have built up a relationship with the parent agribusiness, and abide by the recommendations that they provide. However, as a result of this there is the possibility that there will be an exercise of leadership power upon the farmer.

The ATP exercises leadership power when the farmer enters into a data sharing partnership with them, without understanding the parameters of the agreement, specifically relating to data ownership, data control, and distribution of data, as a result of the farmer accepting the ATP's authority as a service provider. ATPs are promoting the prospective benefits from using ABDA and farmers are being led to use these technologies without fully understanding what they are agreeing to or what can be done with their data, because of their acceptance of the ATPs authority and expertise. The ATP leads the farmer when, by agreeing to their terms for using ABDA, the ATP causes the farmer to share their data without informed consent about who owns this data and what can be done with it, as a result of the ATP's authority in the area.

\section{Coercive Power}

Coercion in an ATP-farmer relationship is when there is a threat to the farmer from leaving the power relationship once it is in place or coercing them into a power relationship in the first place. This coercion of power is the threat against the farmer with legal proceedings, as a result of the contractual agreements that they have entered. Coercive power is demonstrated through the threat of ABDA deprivation, if farmers do not abide by specific policies or conditions of the ATP or if the farmer wants to find a different ATP. Once a relationship has been established with an ATP, it may be very cumbersome to switch to another one, because the farmer has shared their historical data with the ATP and intuitively they would be able to make better decisions about the farmer's land because they have already built up a 
relationship with them, know their needs, and completed much of the data analytics work already. While this may be true, there may be additional reasons for wanting to leave the ATP; such as costs, unfair terms and conditions, or ATP accessibility. Another possibility for farmers would be to use two or more ATPs. However, this would not make any economic sense and would be very inconvenient. It may also give the farmer conflicting answers and messages about how to run their farm. How does a farmer decide between two or more different ATPs? Should the farmer choose A's prescriptions because they have been with them longer, or B's because they are a larger company, for example?

Furthermore, it is unlikely that ATPs will want to share their business with a competitor, so they may make the possibility of the farmer sharing this data quite difficult. Farmers are often contractually restricted from sharing data with other ATPs (Sykuta 2016, p. 68). For example, Monsanto's FieldScripts ${ }^{\circledR}$ program has restrictive intellectual property and data control policies to ensure it adequately protects its investments of prescriptive data sets and algorithms. This is to prevent other ATPs from gaining the knowledge of their R\&D. Farmers cannot share the prescriptive data generated by the ATP and cannot use the prescriptive analytics on fields that they did not agree to. Fundamentally, the user's raw data is their own, but any prescriptive data created by the ATP belongs to them. This makes it impossible to compare prescriptive data with another company. Individuals often look for second opinions before making drastic changes in their lives. They consult a different doctor for a second opinion about their health, they go to a different mechanic and ask their opinion about the diagnosis of the first mechanic, and so on. In the ATP relationship, we are left with the option of trusting the prescriptions of our ATP or else just moving to a different one, with all of the problems of doing so already highlighted.

The types of relationship developed with ATPs makes it very difficult to move to another one because of legal parameters and currently existing relationship with other parts of their business that are intertwined with ABDA provision (such as their chemical and seed business). The farmer may be legally bound to one agribusiness's seed or chemical business, making it problematic to ask a different ATP to provide advice on a competitor's products, which they may not have any knowledge of or be legally permitted to do so. There may be legal restrictions from even allowing them to compare data between two competing ATPs, making it very difficult for farmers to establish a working relationship with any other ATP. If farmers who are using ABDA are suddenly cut off, their progress will diminish or even regress, having an impact on their competitiveness and ability to remain in business. Without having analytics at their disposal, farmers may lose the capacity to make informed decisions about their farm. Therefore, there is distinct pressure on the farmer to conform to guidelines and restrictions implemented by the ATP, so that they do not suffer marketplace vulnerabilities or get cut off from using ABDA by the ATP.

Furthermore, agribusinesses often only permit farmers who are already using their seed or chemical products to avail of ABDA. This forces farmers to use products that they may not want to if they want to use ABDA. For example, 'Pioneer's Field $360^{\mathrm{TM}}$ is limited to farmers using Pioneer seed. FieldScripts ${ }^{\circledR}$ is limited, at present, to Monsanto's DEKALB seed varieties' (Sykuta 2016, p. 63). Monsanto has also limited the use of its FieldScripts technology to farmers who are using machines 
created by their company Precision Planting (Holden 2014). If farmers want to benefit from the use of ABDA, farmers are left with the choice of using the company's other products or run the risk of losing out in the competitive agricultural market. Companies may also use the knowledge acquired through ABDA to sell products at higher prices or sell the farmer products they may not need. Overall, farmers are in a precarious position when it comes to adopting and using ABDA. While ABDA may provide great benefits to improve their farms, their use may also threaten the farmer's autonomy and their ability to compete in the agricultural world. They may be coerced into accepting the stringent policies set out by the ATP so that they can benefit from ABDA, or they may not be able to leave the agreement because they are forced to remain in it for legal or economic reasons.

\section{Forceful Power}

Force as a power is typically meant as physical force, violence or restraint. However, force as a power is not only confined to physical confinements or restraints to do something. Power as force is when 'someone is either physically restrained or brought into motion in order to achieve certain outcomes, or in which someone is intentionally limited to act in a certain way to satisfy his vital interests' (Brey 2007). For example, A can create a situation whereby B has no other choice but to do action $\mathrm{x}$. For example, $\mathrm{A}$ is an agribusiness with ATP services, and they increase their rate on their seeds, chemicals, machinery or ABDA because they know from B's data that they are dependent on these goods and services. If B does not comply with A's new pricing, then they will be removed from service, thus leaving B without the seeds, chemicals, machinery or ABDA that they need to farm and ensure a living. It is a form of monopoly power, but one of force, if B does not abide by A's new policy, they will be without these goods and services that they are dependent upon. The farmer is intentionally limited to abide by the agribusiness's demands to satisfy their vital interests.

Despite this, B could go without ABDA and revert their farm back to a pre-technological state, but then they would be open to the competitiveness of the market, which may eventually force them to be uncompetitive, disadvantaging them and potentially ruining their farm's prosperity. However, the farmer cannot live without seeds, chemicals and farm machinery, as these are integral components to his profession. ${ }^{7}$ Therefore, there is a tension between accepting the increased costs or finding another solution. However, B cannot just move a town or look for another job, as farmers typically work in these careers for their entire lives, do not have the appropriate skills to change profession, and usually do not know any other way of life but the farm. They must comply with A's pricing because going without these goods is not an option and moving to a different town or changing career is also not possible or desirable. However, this exertion of force can only really come about with enough

\footnotetext{
7 It is also important to reiterate the interconnected nature between the agribusiness and their ATP business. The use of machinery, fertilizers, seeds, and chemicals are intertwined with the provision and use of ABDA, so ABDA is not the only factor that can be removed from the farmer's use.
} 
knowledge about the limitations and abilities of the farmer to pay these increasing costs. If the agribusiness/ATP pushes the farmer too far, then they will have to either change career, see if they can somehow live without these goods and services, or change to a different distributor. However, with appropriate knowledge derived from ABDA, the agribusiness may be able to determine the limitations that the farmer can abide by without complete economic destitution.

As a result of the use of ABDA, ATPs may increase their production costs in accordance with what they know the farmer can pay for their goods and services. This information may be derived from the exact data that they are retrieving from the farmer under the auspice of helping them improve their management decisions. ATPs can retrieve information about harvest rates, yield sizes, yield prices, profit margins, and project what these will be in the future. The ATP's price discrimination can be retrieved from the data and aggregations taken from the farm, inputting knowledge of the farmer's yield, the improvements in productivity from previous years, what they are currently paying for the seeds and/or technological services that the agribusiness provides and what they intend to sell their produce for. As a result, they can determine what is possible for the farmer to pay.

Even when agribusinesses can determine how much you are willing-to-pay for their seeds or algorithmic service, they can still stretch this amount further if you are contractually obliged or have no other option. In addition to this, many ATPs are even determining what companies the farmer can sell to (Sykuta 2016). There is the possibility that agribusinesses will be able to use the collected data to calculate specific valuations of commodities, which may lead to control and domination of the market. Ultimately, 'access to such data could be used to speculate in commodities markets with information that is not otherwise knowable to market participants, giving rise to concerns about market manipulation' (Sykuta 2016, p. 65). There is the worry that 'hedge funds might use real-time data at harvest time [...] to speculate in commodity markets' (Kamilaris et al. 2017, p. 29). The ATP knows what the farmer will produce, who they can sell their products to, and what price it will be sold at. As a result, they can determine the exact amount that the farmer is willing to pay for the goods and/or services that they are offering, they can establish what the farmer should sell their harvest for, how much profit should be made by the farmer, and who should receive it. The only possibility of not being forced into these conditions is by moving to a different company, which is becoming more tenuous with the abundance of acquisitions and mergers in recent years, which is veering towards less choice and competition of agricultural suppliers. ${ }^{8}$

ATPs are entering partnerships and acquisitions, in order to procure greater resources and protect their future as ATPs: 'ATPs are increasingly forming alliances or partnerships with each other to access one another's data or knowledge bases.

\footnotetext{
${ }^{8}$ Competition is a fundamental requisite for balanced and fair market-based economies. It is a necessary prerequisite in order to ensure the fair exchange of goods and services. It can be understood as two or more competing entities providing goods or services, under different conditions, in order to attract business. If there is a complete lack of competition, it would lead to a monopoly market, providing goods or services at whatever terms they choose or within the boundaries of acceptance by third parties.
} 
While on the surface these arrangements may be intended as value-adding for the various participants, the arrangements may also be defensive in nature to prevent disputes over data ownership and use' (Sykuta 2016, p. 66). While ATPs are becoming larger and more dominant, small-to-medium enterprises are being swallowed up in takeovers or cannot further compete in the industry. One of the main concerns within the agricultural sector, relating to ABDA, is that particular companies will have too much market control and power, as a result of owning and controlling a large portion of the data. There have recently been several high-profile acquisitions that will amount to the global control of ABDA within the hands of a few powerful conglomerates.

Sykuta states that large ATPs are becoming the 'gatekeeper' of information in the agricultural sector and it becomes very difficult for start-ups to enter the market or for independent developers to improve the algorithms, code and processes involved in the agricultural analytics forecasting. 'This gives rise to concerns about the ability of large incumbent ATPs to hold a competitive advantage over any potential entrants that do not have access to the breadth of data (i.e., data from many farms)' (Sykuta 2016, p. 64). ATPs own the aggregated data that is retrieved and accessed from their repository of farms, along with their own data that they have compiled. In the case of the agricultural industry and the proliferation of ABDA, if the ATP monopolises the market and its competition is no longer able to trade, it becomes a problematic issue for the farmer and the industry.

As a result of these mergers and acquisitions, it may potentially put the farmer in an extremely difficult position as they will have no other options to change agribusiness or ATP. Even with the few options available today, if there is a monopoly marketplace, the farmer is intentionally limited to abide by the agribusiness or ATP's demands to satisfy their vital interests. ABDA may provide agribusinesses with data of what the farmer can pay for goods and services, but the closing down of alternative suppliers through aggressive acquisitions and mergers would ensure a forceful power control over the farmer and the market as a whole. In order to ensure their vital interests, they must abide by price increases and policy changes by the agribusiness, but only to the extent where other options are available. If these alternatives disappear, it puts a greater strain on the farmer, forcing him into a dynamic that they would not have otherwise chosen.

\section{Conclusion}

The world's population is growing, and we will have an extra two billion mouths to feed by 2050 . Our ecological impact is being felt globally and there are persistent efforts to reduce our environmental footprint. Farmers are placed in an extremely precarious position because they are expected to increase their food yields by $70 \%$ but are also concurrently pressured to reduce any environmentally harmful activities. It is a difficult position they find themselves in, with resource limitations already restricting many of their activities. Most farmers are producing as much grain as they can with their current staff levels, knowledge, and abilities. While at the same time, governments are implementing stricter 
environmental regulations. Farmers are desperate for any help they can get, and ABDA offers a glimmer of hope. However, when placed in difficult situations, there is an increased possibility for abuse of power.

This paper categorised five types of power that may become realised in the farmer-ATP dynamic as a result of using ABDA. It was shown that the use and adoption of ABDA may cause issues throughout Brey's five power categorisations: manipulative, seductive, leadership, coercive, and forceful power (Brey 2007).

It was shown that farmers can be prone to abuses of manipulative power by the attraction of using ABDA to grow their farm but being unaware that the data they are giving to ATPs may be used for nefarious purposes such as undercutting land prices and land grabs. It was shown that the use of their data for these purposes would not be condoned by farmers because of the disadvantages in inequities it would bring.

Farmers may also be liable to abuses of power by the seductive nature of ABDA, causing them to accept situations that they would not have done otherwise (for example, the installation of monitors and sensors around their farm, being banned from accessing parts of their machinery, and curtailing many of their freedoms on their own farm).

This paper also highlighted the danger of leadership power in the way that farmers are often unaware of the details within the contracts that they are agreeing to because of the authoritative trust placed in the hands of the ATP. It was shown that despite farmers being concerned about data ownership, privacy and informationsharing, the leadership power of the ATP causes them to agree to terms and conditions they are not informed about.

ATPs also exercise coercive power with the threat of ABDA deprivation if the farmer does not abide by these contractual requirements. They are coerced into remaining with the ATP for fear of reprisal, either economically or legally. Farmers feel pressured to remain with their ATP because of difficulties associated with changing provider. Furthermore, the attraction of ABDA may often cause farmers to purchase additional goods from the ATP, which they would not have otherwise done.

Lastly, there is the possibility that ATPs will use the data derived from farms to implement a form of price discrimination to determine the exact price farmers can and will pay for their goods and services. With the abundance of mergers and acquisitions, it looks as though farmers will be left with fewer choices of moving suppliers and may become prone to forceful power restrictions to remain with their agricultural provider in the future.

Overall, this paper provides a clear demonstration of how the use and implementation of ABDA may cause issues in the farming community, specifically relating to shifting power dynamics. This paper illustrated how Brey's five types of power can be illustrated in the agricultural sector, using ABDA, and provided a theoretical account of how these powers would materialise. It did not explicitly evaluate these power dynamics in a prescriptive manner, but instead, lay the groundwork for future development and research towards normative evaluations of these power structures. 
Funding Open access funding provided by Royal Institute of Technology.

Open Access This article is distributed under the terms of the Creative Commons Attribution 4.0 International License (http://creativecommons.org/licenses/by/4.0/), which permits unrestricted use, distribution, and reproduction in any medium, provided you give appropriate credit to the original author(s) and the source, provide a link to the Creative Commons license, and indicate if changes were made.

\section{References}

Allen, J. (2009). Powerful geographies: Spatial shifts in the architecture of globalization. In S. R. Clegg \& M. Haugaard (Eds.), The Sage handbook of power. London: Sage Publications Ltd.

American Farm Bureau. (2016). Farm bureau surveys: Farmers want to control their own data. American Farm Bureau Federation [website]. https://www.fb.org/newsroom/farm-bureau-survey-farme rs-want-to-control-their-own-data. Accessed May 15, 2019.

Aquinas, T. (1972). Question 110: Lying. In Summa theologiae (Volume 41: Virtues of Justice in the Human Community). New York: McGraw-Hill.

Augustine, S. (1952). On lying. In R. J. Deferrari (Ed.), Fathers of the Church (Volume 16: Treatises on Various Subjects). New York: Fathers of the Church.

Beck, U. (2005). Power in the global age: A new global political economy. Cambridge: Polity Press.

Bennett, J. (2015). Agricultural big data: Utilisation to discover the unknown and instigate practice change. Farm Policy Journal, 12(1), 43-50.

Berlin, I. (1958). Two concepts of liberty: An inaugural lecture delivered before the University of Oxford on 31 October 1958. Clarendon.

Bernardi, A. (2013). iGreen-intelligent technologies for public-private knowledge management in agriculture. KI-Künstliche Intelligenz, 27(4), 347-350.

Brey, P. (2007). The technological construction of social power. Social Epistemology, 22(1), 71-95.

Bunge, J. (2017). Agricultural giants teach computers to farm. In The Wall Street Journal https:// www.wsj.com/articles/leaf-recognition-technology-agriculture-digs-into-artificial-intelligen ce-1505300400. Accessed May 15, 2019.

Carolan, M. (2017). Publicising food: Big data, precision agriculture, and co-experimental techniques of addition. Sociologia Ruralis, 57(2), 135-154.

Clegg, S., \& Haugaard, M. (2009). Discourse of power. In S. R. Clegg \& M. Haugaard (Eds.), The Sage handbook of power. London: Sage Publications Ltd.

Coble, K. H., Mishra, A. K., Ferrell, S., \& Griffin, T. (2018). Big data in agriculture: A challenge for the future. Applied Economic Perspectives and Policy, 40(1), 79-96.

Connolly, W. E. (1974). The terms of political discourse. Lexington, MA: D.C. Heath.

Dengel, A. (2013). Special issue on artificial intelligence in agriculture. KI-Künstliche Intelligenz, 27(4), 309-311.

Fleischmann, P., Föhst, T., \& Berns, K. (2013). Detection of field structures for agricultural vehicle guidance. KI-Künstliche Intelligenz, 27(4), 351-357.

Food and Agricultural Organisation, The UN. (2009). 2050: A third more mouths to feed. FAO [website]. http://www.fao.org/news/story/en/item/35571/icode/.

GMO Answers. (2014). How long have genetically modified foods been used? GMO Answers [website]. https://gmoanswers.com/ask/how-long-have-genetically-modified-foods-been-used. Accessed May $15,2019$.

Göhler, G. (2009). 'Power to' and 'power over'. In S. R. Clegg \& M. Haugaard (Eds.), The Sage handbook of power. London: Sage Publications Ltd.

Greene, L. (2019). Power. Routledge Encyclopedia of Philosophy. https://doi.org/10.4324/97804 15249126-S046-1.

Griepentrog, H. W., Dühring Jaeger, C. L., \& Paraforos, D. S. (2013). Robots for field operations with comprehensive multilayer control. KI-Künstliche Intelligenz, 27(4), 325-333.

Haugaard, M. (2003). Reflections on seven ways of creating power. European Journal of Social Theory, 6(1), 87-113.

Haugaard, M. (2012a). Power and truth. European Journal of Social Theory, 15(1), 73-92. 
Haugaard, M. (2012b). Rethinking the four dimensions of power: Domination and empowerment. Journal of Political Power, 15(1), 33-54.

Haugaard, M. (2015). Concerted power over. Constellations, 22(1), 147-158.

Heubuch, M. (2016). Land rush: The sellout of Europe's farmland. The Greens: European Free Alliance. https://www.maria-heubuch.eu/fileadmin/heubuch/pdf2016/20161110land_rush.pdf. Accessed May 15, 2019.

Hoard's Dairyman Staff. (2012). First U.S. milking robot factory opens next week. Hoards [website]. https://hoards.com/blog-4645-first-us-milking-robot-factory-opens-next-week.html. Accessed May 15, 2019.

Hobbes, T. (1968). In C. B. Macpherson (Ed.), Leviathan. Harmondsworth: Penguin.

Holden, J. (2014). Farmers up in arms over potential misuse of data. The Irish Times. https://www. irishtimes.com/business/farmers-up-in-arms-over-potential-misuse-of-data-1.1863181. Accessed May 15, 2019.

Janzen, T. J., \& Ristino, L. (2018). USDA and agricultural data: Improving productivity while protecting privacy. Agree: Transforming Food \& Ag Policy. http://www.foodandagpolicy.org/sites/default/files /USDA \%20and\%20Ag\%20Data-Improving\%20Productivity\%20While\%20Protecting\%20Producer \%20Privacy.pdf. Accessed May 15, 2019.

Kamilaris, A., Kartakoullis, A., \& Prenafeta-Boldú, F. X. (2017). A review on the practice of big data analysis in agriculture. Computers and Electronics in Agriculture, 143, 23-37.

Kant, I. (1996). Groundwork of the metaphysics of morals, The metaphysics of morals, and on a supposed right to lie from philanthropy. In A. W. Wood \& M. J. Gregor (Eds.), Practical philosophy (M. J. Gregor Trans.). Cambridge: Cambridge University Press.

Kshetri, N. (2014). The emerging role of big data in key development issues: Opportunities, challenges, and concerns. Big Data \& Society, 1(2), 1-20.

Lukes, S. (1974). Power: A radical view. London: Macmillan.

MacIntyre, A. (1995). Truthfulness, lies, and moral philosophers: What can we learn from Mill and Kant? The Tanner Lectures on Human Values, Salt Lake City: University of Utah Press, 16, 307-361.

Murray, S. (2007). The world's biggest industry. Forbes. https://www.forbes.com/2007/11/11/growt h-agriculture-business-forbeslife-food07-cx_sm_1113bigfood.html\#7cb9e47d373e. Accessed May $15,2019$.

NASA. (2018). How NASA and John Deere helped tractors drive themselves. NASA [website]. https:// www.nasa.gov/feature/directorates/spacetech/spinoff/john_deere. Accessed May 15, 2019.

National Museum of American History. (2018). Precision farming. The National Museum of American History [website], http://americanhistory.si.edu/american-enterprise-exhibition/new-perspectives/ precision-farming. Accessed May 15, 2019.

New Eastern Outlook. (2015). Monsanto buying lands. Oakland Institute [website]. https://www.oakla ndinstitute.org/monsanto-buying-lands. Accessed May 15, 2019.

Pham, X., \& Stack, M. (2018). How data analytics is transforming agriculture. Business Horizons, 61, $125-133$.

Popa, C. (2011). Adoption of artificial intelligence in agriculture. Bulletin of University of Agricultural Sciences and Veterinary Medicine Cluj-Napoca. Agriculture, 68(1), 284-293.

PrecisionHawk. (2018). How BASF uses drones to measure turf health. PrecisionHawk [website]. https ://www.precisionhawk.com/media/topic/how-basf-uses-drones-to-measure-turf-health/. Accessed May 15, 2019.

Scheuren, S., et al. (2013). Spatio-temporally constrained planning for cooperative vehicles in a harvesting scenario. KI-Künstliche Intelligenz, 27(4), 341-346.

Siegler, F. A. (1966). Lying. American Philosophical Quarterly, 3, 128-136.

Sykuta M. (2012). The fallacy of 'competition' in agriculture. Introduction to the Ethics and Economics of Agrifood Competition: Connotations, Complications and Commentary. https://doi. org/10.1007/978-94-007-6274-9_4.

Sykuta, M. E. (2016). Big data in agriculture: Property rights, privacy and competition in ag data services. The International Food and Agribusiness Management Review, 19, 57-74.

Publisher's Note Springer Nature remains neutral with regard to jurisdictional claims in published maps and institutional affiliations. 